\title{
Influence of the Protonatable Site in the Photo-Induced Proton-Coupled Electron Transfer between Rhenium(I) Polypyridyl Complexes and Hydroquinone
}

\author{
Fernando S. Prado, Sinval F. Sousa, Antonio Eduardo H. Machado and \\ Antonio Otavio T. Patrocinio*
}

\begin{abstract}
Laboratório de Fotoquímica e Ciência de Materiais (LAFOT-CM), Instituto de Química, Universidade Federal de Uberlândia, 38400-902 Uberlândia-MG, Brazil
\end{abstract}

\begin{abstract}
In the present work the influence of the distance of the protonatable site of different ancillary ligands to the metal center on the luminescence quenching of $\mathrm{Re}^{\mathrm{I}}$ polypyridyl complexes by hydroquinone are evaluated by means of experimental and theoretical studies. In these systems, it is expected the occurrence of proton-coupled electron transfer (PCET) reactions upon excitation, which is a key process in solar-to-fuels energy conversion. The series $f a c-\left[\operatorname{Re}(\mathrm{CO})_{3}(2,2-\mathrm{bpy})(\mathrm{L})\right] \mathrm{PF}_{6}$, $\mathrm{L}=$ pyridine, 1,4-pyrazine, 4,4'-bipyridyl, 1,2-bis-(4-pyridyl)ethane were synthesized and the luminescence quenching rate constant $\left(\mathrm{k}_{\mathrm{q}}\right)$ by hydroquinone in $\mathrm{CH}_{3} \mathrm{CN}$ and $1: 1 \mathrm{CH}_{3} \mathrm{CN} / \mathrm{H}_{2} \mathrm{O}$ were determined by steady-state and lifetime measurements. In bare acetonitrile, the 1,4-pyrazine exhibits the higher $\mathrm{k}_{\mathrm{q}}(3.49 \pm 0.02) \times 10^{9} \mathrm{~L} \mathrm{~mol}^{-1} \mathrm{~s}^{-1}$ among the species investigated, followed by $4,4^{\prime}$-bipyridyl $\left(\mathrm{k}_{\mathrm{q}}=2.50 \pm 0.02\right) \times 10^{9} \mathrm{~L} \mathrm{~mol}^{-1} \mathrm{~s}^{-1}$. In $1: 1 \mathrm{CH}_{3} \mathrm{CN} / \mathrm{H}_{2} \mathrm{O}$, the $\mathrm{k}_{\mathrm{q}}$ values for all complexes are very similar evidencing the role of water molecules as proton acceptor following the reductive quenching of the complexes by hydroquinone. $\mathrm{In}_{\mathrm{CH}_{3} \mathrm{CN}}$, the proton release for the solvent is not spontaneous and the higher basicity of the coordinated 1,4-pyrazine and 4,4'-bipyridyl in relation to 1,2-bis-(4-pyridyl)ethane after metal-to-ligand charge transfer (MLCT) excitation contributes to the proton transfer step. These results are corroborated by time-dependent density functional theory (TD-DFT) calculations. Moreover, the low H/D kinetic isotope effect (KIE) in 3:1 $\mathrm{CH}_{3} \mathrm{CN} / \mathrm{X}_{2} \mathrm{O}$ ( $\mathrm{X}=\mathrm{H}$ or $\mathrm{D}$ ) confirms that the major PCET pathway is the electron transfer followed by proton transfer, but for 1,4-pyrazine and 4,4'-bipyridyl the concerted proton-electron transfer seems to play a role at high hydroquinone concentrations.
\end{abstract}

Keywords: proton coupled electron transfer, $\mathrm{Re}^{\mathrm{I}}$ complexes, luminescence quenching

\section{Introduction}

Proton-coupled electron transfer (PCET) plays a key hole in several chemical and biological systems and there is a growing interest in understanding its mechanisms. ${ }^{1-4}$ For example, one can cite the importance of PCET in key reactions in photosynthesis (equation 1), ${ }^{5}$ in which the transfer of $12 \mathrm{e}^{-}$and $12 \mathrm{H}^{+}$are driven by at least 24 photons $^{6}$ or photo-driven solar fuels production through water splitting (equation 2), ${ }^{7}$ or solar driven water reduction of $\mathrm{CO}_{2}$ to hydrocarbons (equation 3 ). ${ }^{2}$ Natural photosynthesis leads to an impressive energy storage, with ca. $10^{11}$ tons of carbon stored annually and ca. $10^{18} \mathrm{~kJ}$ of energy. All these processes involve the accumulation of multiple redox equivalents through PCET in a catalytic center in such a way that no high reactive radical intermediates are

*e-mail: otaviopatrocinio@iqufu.ufu.br formed. Thus, mechanistic studies on photo-driven PCET reactions are especially valuable for the development of artificial systems able to mimic the natural photosynthesis and convert solar energy into fuels. Different theoretical aspects of PCET have been studied in different systems as summarized by Huynh ${ }^{8}$ and, more specifically for $\mathrm{d}^{6}$ metal complexes by Wenger ${ }^{9,10}$ and Meyer and co-workers. ${ }^{11}$

$$
\begin{aligned}
& 6 \mathrm{CO}_{2}+6 \mathrm{H}_{2} \mathrm{O}+24 \mathrm{hv} \rightarrow \mathrm{C}_{6} \mathrm{H}_{12} \mathrm{O}_{6}+\mathrm{O}_{2}\left(\Delta \mathrm{G}^{0}=29.1 \mathrm{eV}\right) \\
& 2 \mathrm{H}_{2} \mathrm{O}+4 \mathrm{hv} \rightarrow \mathrm{O}_{2}+2 \mathrm{H}_{2}\left(\Delta \mathrm{G}^{0}=4.92 \mathrm{eV}\right) \\
& 2 \mathrm{H}_{2} \mathrm{O}+\mathrm{CO}_{2}+8 \mathrm{hv} \rightarrow \mathrm{CH}_{4}+2 \mathrm{O}_{2}\left(\Delta \mathrm{G}^{0}=10.3 \mathrm{eV}\right)
\end{aligned}
$$

Among the different chemical species that can undergo photon-driven PCET, $\mathrm{d}^{6}$ metal complexes call special attention due to their high visible light absorption, synthetic flexibility and chemical stability. ${ }^{3}$ Despite their well-known photoredox chemistry, acid/basic character can be added by the corrected choice of the ligands aiming the occurrence 
of combined proton/electron transfers. These species generally exhibit long-lived luminescent metal-to-ligand $\left({ }^{3} \mathrm{MLCT}\right)$ excited states in fluid solution, enabling the investigation of PCET by emission quenching studies, while possible intermediates are probed by transient absorption spectroscopy. Different reports can be found in the literature involving $\mathrm{Ru}^{\mathrm{II}}$ polypyridyl complexes ${ }^{12-16}$ and, more recently, $\mathrm{Re}^{\mathrm{I}}$ tricarbonyl diimines ${ }^{17-21}$ and Ir ${ }^{\mathrm{III}}$ complexes. ${ }^{22,23}$ Phenols have been typically used as quenchers in these studies, partly by their relevant function in biological systems, but also by its simplicity which make mechanistic investigations easier.

In this work, we focus our attention in the PCET reactions of $\mathrm{Re}^{\mathrm{I}}$ tricarbonyl polypyridyl complexes with hydroquinone $\left(\mathrm{H}_{2} \mathrm{Q}\right)$ (Scheme 1). MLCT excitation of $\mathrm{Re}^{\mathrm{I}}$ complexes leads to reductive quenching of the luminescence by hydroquinone and a proton release to yield the semiquinone radical (HQ'). The reaction can occur basically by three different pathways that include electron transfer (ET) followed by proton transfer (PT), ET-PT, proton transfer followed by electron transfer (PT-ET) and the concerted electron-proton transfer (EPT), in which electrons and protons are transferred simultaneously. The EPT pathway avoids the formation of reaction intermediates and frequently represents a relatively low energy barrier pathway. Identification of the PCET mechanism for a given system requires a thermodynamic analyses (redox potentials, acidity constants), along with transient studies and observation of kinetic isotope effects (KIE).

In a first study on these systems, Stewart et al. ${ }^{24}$ have identified two competing PCET pathways of $f a c-\left[\mathrm{Re}^{\mathrm{II}}(\mathrm{CO})_{3}\left(2,2-\mathrm{bpy} \mathbf{y}^{\bullet}\right)(4,4-\mathrm{bpy})\right]^{*+}$, 2,2-bpy $=2,2^{\prime}$-bipyridyl and 4,4-bpy $=4,4^{\prime}$ '-bipyridyl with hydroquinone. In one pathway, the MLCT excited state is quenched by electron transfer from $\mathrm{H}_{2} \mathrm{Q}$ followed by proton transfer to yield $f a c$ - $\left[\operatorname{Re}^{\mathrm{I}}(\mathrm{CO})_{3}(2,2-\mathrm{bpy})\left(4,4-\mathrm{bpyH}^{\bullet}\right)\right]^{+}$. The protonation of 4,4-bpy triggers an intramolecular electron transfer between the bipyridyl ligands. At high $\mathrm{H}_{2} \mathrm{Q}$ concentrations, a preassociation step occurs between the complex in the ground state and the quencher, leading to an EPT reaction upon excitation.

Bronner and Wenger ${ }^{20}$ have then investigated the influence of protonatable sites on PCET reaction by studying

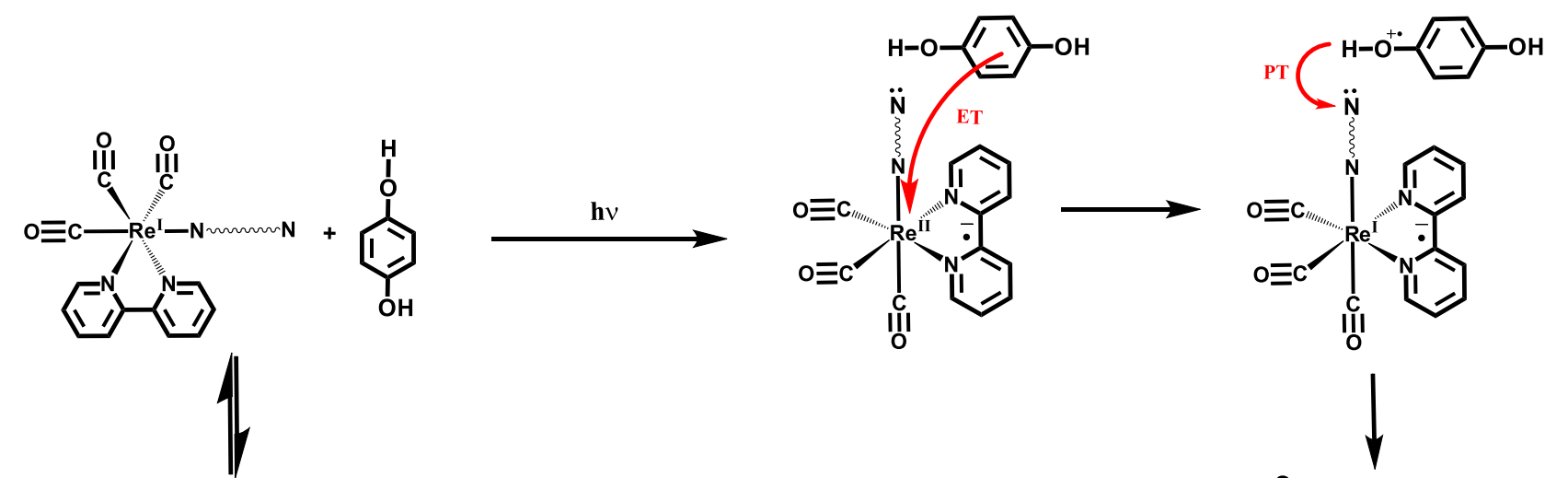

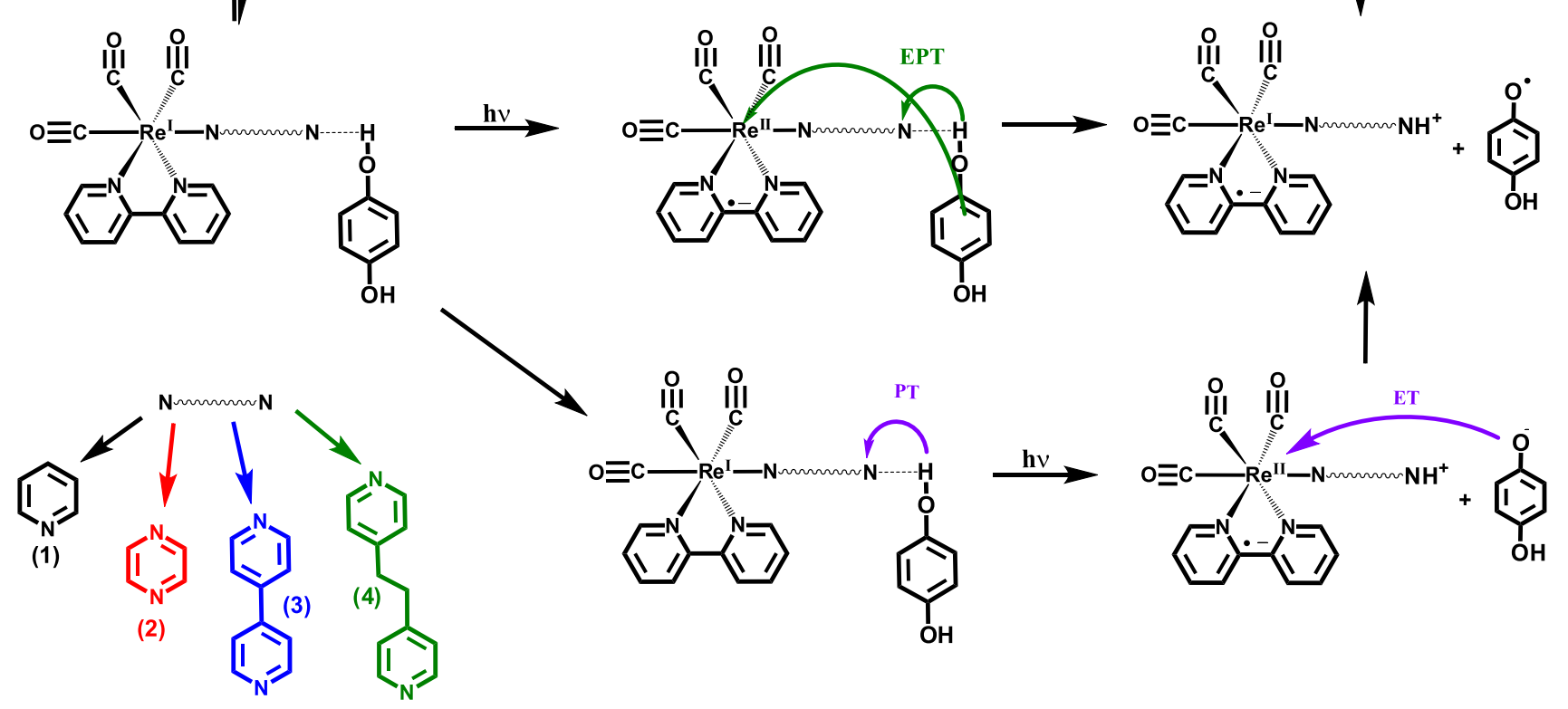

Scheme 1. Possible reaction pathways for the photoinduced PCET between $\operatorname{Re}(\mathrm{I})$ complexes and hydroquinone. 
the photoreaction dynamics of $f a c-\left[\operatorname{Re}(\mathrm{CO})_{3}(2,2-\mathrm{bpy})(\mathrm{pz})\right]^{+}$ and $f a c-\left[\operatorname{Re}(\mathrm{CO})_{3}(\mathrm{bpz})(\mathrm{py})\right]^{+}, \mathrm{pz}=$ pyrazine, $\mathrm{bpz}=2,2^{\prime}$-bipyrazine and py = pyridine, with 4-cyanophenol. Both complexes exhibited PCET chemistry with similar rate constants, despite the differences on the ${ }^{3}$ MLCT energies and excited state acidity. The authors have found that for $f a c-\left[\operatorname{Re}(\mathrm{CO})_{3}(2,2-\mathrm{bpy})(\mathrm{pz})\right]^{+}, \mathrm{EPT}$ mechanism is the most viable mechanism thermodynamically ( $\mathrm{KIE}=1.8 \pm 0.2$ ), while for $f a c-\left[\operatorname{Re}(\mathrm{CO})_{3}(\mathrm{bpz})(\mathrm{py})\right]^{+}$, the PT-ET pathway cannot be ruled out.

Further, we have investigated the influence of the MLCT energies and lifetimes on the photoreductive quenching by hydroquinone in a $\mathrm{fac}-\left[\operatorname{Re}(\mathrm{CO})_{3}(\mathrm{NN})(\mathrm{bpa})\right]^{+}$, bpa $=1,2$-bis-(4-pyridyl)ethane, $\mathrm{NN}=1,10$-phenanthroline (phen), pyrazino[2,3-f][1,10]-phenanthroline (dpq), and dipyrido[3,2-a:2'3'-c]phenazine (dppz). ${ }^{25}$ In these series the protonatable site was the remote $\mathrm{N}$-atom in the bpa ligand and the complexes with phen and dpq as ligand exhibited PCET chemistry in $1: 1 \mathrm{CH}_{3} \mathrm{CN} / \mathrm{H}_{2} \mathrm{O}$. In this manuscript, we have synthesized a series of $\mathrm{Re}^{\mathrm{I}}$ complexes (1-4 in Scheme 1) with very similar ${ }^{3}$ MLCT energies to evaluate how the distance between the metal center and the protonatable site can affect the mechanism of luminescence quenching by hydroquinone and the PCET chemistry.

\section{Experimental}

\section{Materials}

All solvents employed in the spectroscopic studies were high-performance liquid chromatography (HPLC) grade. Anhydrous acetonitrile (Aldrich) was used as solvent in all electrochemical measurements. $\left[\mathrm{ClRe}(\mathrm{CO})_{5}\right]$, 2,2'-bipyridyl (2,2-bpy), pyridine (py), pyrazine (pz), 4,4'-bipyridyl (4,4-bpy), 1,2-bis-(4-pyridyl)ethane (bpa), ammonium hexafluorophosphate, trifluoromethanesulfonic acid, tetrabutylammonium hexafluorophosphate, deuterion oxide and hydroquinone were purchased from Aldrich and used as received. Ultrapure water (conductivity of $0.055 \mathrm{~S} \mathrm{~cm}^{-1}$ at $25^{\circ} \mathrm{C}$ ) was employed in all experiments.

\section{Methods}

${ }^{1} \mathrm{H}$ nuclear magnetic resonance (NMR) spectra were recorded in $\mathrm{CD}_{3} \mathrm{CN}$ (Aldrich) in a Bruker AVANCE III $500,11.75$ Tesla, spectrometer operating at $500.13 \mathrm{MHz}$ for ${ }^{1} \mathrm{H}$ of the laboratory of nuclear magnetic resonance (LabRMN) of the Federal University of Goiás. Absorbance spectra were acquired in an UV-2501 BC (Shimadzu) spectrophotometer using $1.000 \mathrm{~cm}$ quartz cuvette. Electrochemical measurements were carried out in an
Autolab PGSTAT 204 potentiostat/galvanostat under argon atmosphere. All measurements were performed in anhydrous acetonitrile, using tetrabutylammonium hexafluorophosphate $\left(10^{-2} \mathrm{~mol} \mathrm{~L}^{-1}\right)$ as support electrolyte. Glassy carbon was employed as working electrode along with a $\mathrm{Pt}$ wire as counter electrode and the reference electrode was $\mathrm{Ag} / \mathrm{AgCl}$ in $3 \mathrm{~mol} \mathrm{~L}^{-1} \mathrm{KCl}$. Ferrocene ( $\mathrm{Fc}$, $0.63 \mathrm{~V}$ vs. NHE) ${ }^{26}$ was employed as internal reference.

Steady state emission experiments were carried out in a Hitachi F4500 or a Horiba FluoroMax-4 spectrofluorometer in argon-degassed acetonitrile or 1:1 $\mathrm{CH}_{3} \mathrm{CN} / \mathrm{H}_{2} \mathrm{O}$ solutions at $298 \mathrm{~K}$ placed at Starna GL14 $1.000 \mathrm{~cm}$ quartz cuvettes fitted with a rubber septum as described elsewhere. ${ }^{25}$ Typical concentrations employed in the experiments were between $1 \times 10^{-5}$ and $5 \times 10^{-5} \mathrm{~mol} \mathrm{~L}^{-1}$, in such a way that the absorbance at the excitation wavelength was between 0.1 and 0.3 . Emission quantum yields were determined as described elsewhere, ${ }^{27}$ using $f a c-\left[\mathrm{ClRe}(\mathrm{CO})_{3}(\mathrm{phen})\right]$, phen $=1,10$-phenanthroline, as standard $\left(\varphi_{\mathrm{em}}=0.018\right.$ in $\left.\mathrm{CH}_{3} \mathrm{CN}, 298 \mathrm{~K}\right)$. Quenching experiments were carried out in acetonitrile or 1:1 $\mathrm{CH}_{3} \mathrm{CN} / \mathrm{H}_{2} \mathrm{O}$ mixture in the presence of hydroquinone with concentrations ranging from $10^{-4}$ to $10^{-2} \mathrm{~mol} \mathrm{~L}^{-1}$. Quenching rate constants reported are average results of three independent experiments at least.

Emission lifetimes and time-resolved emission quenching experiments were obtained in a homemade system previously described. ${ }^{25,28}$ Samples were pumped with the third harmonic $(355 \mathrm{~nm})$ of an Nd:YAG pulsed laser (Quantel Brio, 5ns FWHM; $20 \mathrm{~Hz}$ repetition rate). The measurements were performed in argon degassed acetonitrile or 1:1 $\mathrm{CH}_{3} \mathrm{CN} / \mathrm{H}_{2} \mathrm{O}$ solutions placed in a $1.000 \mathrm{~cm}$ quartz cuvette and with similar concentrations employed in the steady-state experiments. The reported lifetimes are the average results of 50 decay traces probed at the respective emission maxima.

\section{Computational details}

The calculations were done using the functional density theory (DFT) and its time-dependent (TD-DFT) approach, applying the m06 functional. ${ }^{29}$ The structure of the ground state was optimized using the segmented all-electron relativistically contracted atomic basis, combined to the Douglas-Kroll-Hess (SARC-DKH) for rhenium(I) I $^{30,31}$ and Def2-TZVPP (orbitals with effective core potential) for the other elements. ${ }^{32}$ The structures, after optimization, did not show imaginary vibrational frequencies. The vertical absorption spectrum (60 singlet excited states) and the energy of some of the lowest triplet non-relaxed states were also computed. All calculations were performed using the solvation model IEFPCM (5) to describe the solvation of 
the complex in acetonitrile. All calculations were done using Gaussian09 revision E.01.33

\section{Synthesis}

The syntheses of $f a c-\left[\operatorname{Re}(\mathrm{CO})_{3}(2,2-\mathrm{bpy})(\mathrm{L})\right] \mathrm{PF}_{6}$ (Scheme 1) were performed following the procedures described in the literature ${ }^{34}$ with some modifications. Briefly, $\left[\mathrm{ClRe}(\mathrm{CO})_{5}\right]$ was mixed with an excess of 2,2-bpy in toluene and refluxed for five hours to yield the chlorido complex, $f a c$ - $\left[\mathrm{ClRe}(\mathrm{CO})_{3}(2,2\right.$-bpy)]. The solid was filtered and recrystallized from dichloromethane by addition of $n$-pentane. Then, $f a c$ - $\left[\mathrm{ClRe}(\mathrm{CO})_{3}(2,2\right.$-bpy $\left.)\right]$ was suspended in argon-saturated $\mathrm{CH}_{2} \mathrm{Cl}_{2}$ and trifluoromethanesulfonic acid was added to yield the intermediate $f a c$ - $\left[\operatorname{Re}(\mathrm{CO})_{3}(2,2-b p y)\left(\mathrm{CF}_{3} \mathrm{SO}_{3}\right)\right]$, which was precipitated by slow addition of ethyl ether. The fac- $\left[\operatorname{Re}(\mathrm{CO})_{3}(2,2-\right.$ bpy $\left.)(\mathrm{L})\right] \mathrm{PF}_{6}$ complexes were obtained by reacting one equivalent of $f a c-\left[\operatorname{Re}(\mathrm{CO})_{3}(2,2-\right.$ bpy $\left.)\left(\mathrm{CF}_{3} \mathrm{SO}_{3}\right)\right]$ with 2 equivalents of the desired ancillary ligand in methanol. After six hours refluxing, the products were precipitated by slow addition of ammonium hexafluorophosphate, being the solids separated by filtration, washed with water to remove the $\mathrm{NH}_{4} \mathrm{PF}_{6}$ excess, and then, with ethyl ether.

\section{fac- $\left[\operatorname{Re}(\mathrm{CO})_{3}(2,2-\mathrm{bpy})(\mathrm{py})\right] \mathrm{PF}_{6}(\mathbf{1})$}

Yield: $72 \%$. Anal. calcd. for $\mathrm{C}_{19} \mathrm{H}_{17} \mathrm{~N}_{3} \mathrm{O}_{3} \mathrm{RePF}_{6}$ : C, 33.22; H, 2.00; N, 6.45\%. Found: C, 33.02; H, 2.14; N, 6.34\%. ${ }^{1} \mathrm{H}$ NMR $\left(500.1 \mathrm{MHz}, \mathrm{CD}_{3} \mathrm{CN}\right) \delta 9.20(\mathrm{~d}, 2 \mathrm{H}$, $J 5.5 \mathrm{~Hz}), 8.35(\mathrm{~d}, 2 \mathrm{H}, J 8.5 \mathrm{~Hz}), 8.25(\mathrm{~d}, 2 \mathrm{H}, J 8.0 \mathrm{~Hz})$, $8.22(\mathrm{~d}, 2 \mathrm{H}, J 5.5 \mathrm{~Hz}), 7.83(\mathrm{t}, 1 \mathrm{H}, J$ 8.0, $7.8 \mathrm{~Hz}), 7.77$ (t, $2 \mathrm{H}, J 6.0,6.5 \mathrm{~Hz}), 7.28$ (t, 2H, J 7.0, 7.0 Hz).

\section{$\mathrm{fac}-\left[\operatorname{Re}(\mathrm{CO})_{3}(2,2-\mathrm{bpy})(\mathrm{pz})\right] \mathrm{PF}_{6}(\mathbf{2})$}

Yield: $75 \%$. Anal. calcd. for $\mathrm{C}_{18} \mathrm{H}_{16} \mathrm{~N}_{4} \mathrm{O}_{3} \mathrm{RePF}_{6} \cdot \mathrm{H}_{2} \mathrm{O}$ : C, 31.54; H, 2.65; N, 8.17\%. Found: C, 31.20; H, 2.31; $\mathrm{N}, 8.56 \%$. ${ }^{1} \mathrm{H}$ NMR $\left(500.1 \mathrm{MHz}, \mathrm{CD}_{3} \mathrm{CN}\right) \delta 9.17(\mathrm{~d}, 2 \mathrm{H}$, $J 5.0 \mathrm{~Hz}), 8.53(\mathrm{~d}, 2 \mathrm{H}, J 2.0 \mathrm{~Hz}), 8.39(\mathrm{~d}, 2 \mathrm{H}, J 8.0 \mathrm{~Hz})$, $8.26(\mathrm{t}, 2 \mathrm{H}, J$ 8.0, $7.8 \mathrm{~Hz}), 8.20(\mathrm{~d}, 2 \mathrm{H}, J 2.0 \mathrm{~Hz}), 7.78(\mathrm{t}$, $2 \mathrm{H}, J 6.5,6.5 \mathrm{~Hz})$.

fac- $\left[\operatorname{Re}(\mathrm{CO})_{3}(2,2-\right.$ bpy $\left.)(4,4-\mathrm{bpy})\right] \mathrm{PF}_{6}$ (3)

Yield: $69 \%$. Anal. calcd. for $\mathrm{C}_{24} \mathrm{H}_{20} \mathrm{~N}_{4} \mathrm{O}_{3} \mathrm{RePF}_{6} \cdot \mathrm{H}_{2} \mathrm{O}$ : C, 37.85; H, 2.91; N, 7.36\%. Found: C, 37.07; H, 2.47; $\mathrm{N}, 7.86 \% .{ }^{1} \mathrm{H}$ NMR $\left(500.1 \mathrm{MHz}, \mathrm{CD}_{3} \mathrm{CN}\right) \delta 9.22(\mathrm{~d}, 2 \mathrm{H}$, $J 5.5 \mathrm{~Hz}), 8.64(\mathrm{~d}, 2 \mathrm{H}, J 3.0 \mathrm{~Hz}), 8.36(\mathrm{~d}, 2 \mathrm{H}, J 8.5 \mathrm{~Hz}), 8.30$ $(\mathrm{d}, 2 \mathrm{H}, J 4.0 \mathrm{~Hz}), 8.29$ (t, 2H, J 8.0, $8.0 \mathrm{~Hz}), 7.78(\mathrm{t}, 2 \mathrm{H}$, $J 6.5,6.5 \mathrm{~Hz}), 7.56(\mathrm{~d}, 2 \mathrm{H}, J 4.0 \mathrm{~Hz}), 7.51(\mathrm{~d}, 2 \mathrm{H}, J 3.5 \mathrm{~Hz})$.

fac-[Re(CO) $)_{3}(2,2-$ bpy $)($ bpa $\left.)\right] \mathrm{PF}_{6}(4)$

Yield: 50\%. Anal. calcd. for $\mathrm{C}_{26} \mathrm{H}_{24} \mathrm{~N}_{4} \mathrm{O}_{3} \mathrm{RePF}_{6} \cdot \mathrm{H}_{2} \mathrm{O}$ :
C, 39.54; H, 3.32; N, 7.09\%. Found: C, 39.27; H, 2.64; $\mathrm{N}, 7.25 \% .{ }^{1} \mathrm{H}$ NMR $\left(500.1 \mathrm{MHz}, \mathrm{CD}_{3} \mathrm{CN}\right) \delta 9.17(\mathrm{~d}, 2 \mathrm{H}$, $J 5.0 \mathrm{~Hz}), 8.35(\mathrm{~d}, 4 \mathrm{H}, J 9.0 \mathrm{~Hz}), 8.24(\mathrm{t}, 2 \mathrm{H}, J 8.0,7.8 \mathrm{~Hz})$, 8.04 (d, 2H, J 5.0 Hz), $7.76(\mathrm{t}, 2 \mathrm{H}, J 6.0,6.3 \mathrm{~Hz}), 7.07$ (s, 4H), 2.84 (dd, 4H, J 7.0, 20.0 Hz).

\section{Results and Discussion}

\section{Spectroscopic and photophysical characterization}

The electronic spectra of the four complexes investigated in this work are presented in Figure 1. One can observe that the electronic spectra of these $\mathrm{Re}^{\mathrm{I}}$ complexes are very similar. At higher energy, light absorption is dominated by internal transitions of the pyridyl ligands, while the lowest absorption bands are broad with molar absorptivity in the order of $10^{3} \mathrm{~L} \mathrm{~mol}^{-1} \mathrm{~cm}^{-1}$, which is typical of metal-to-ligand charge transfer transitions (MLCT). ${ }^{34,35}$

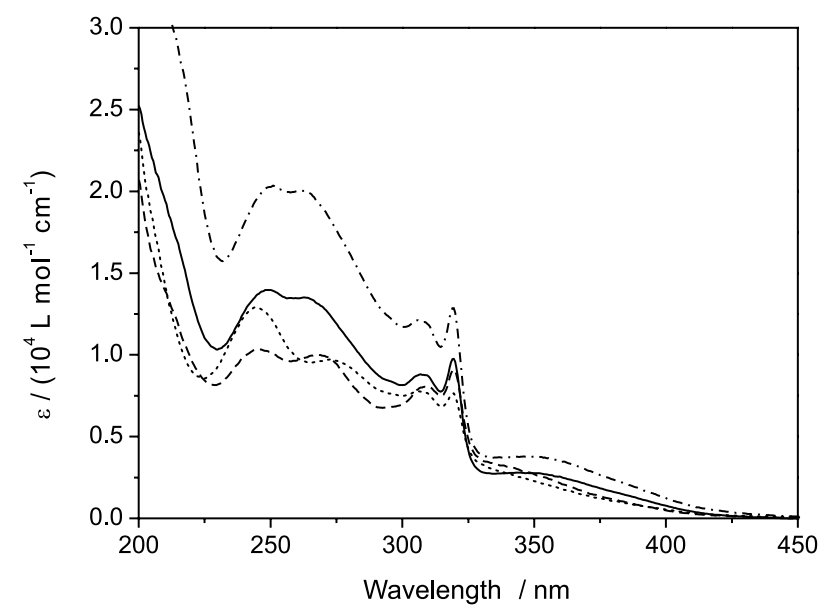

Figure 1. Electronic absorption spectra of complexes 1 (-), 2 (--), $3(\ldots)$ and $4(-\cdot)$ in $\mathrm{CH}_{3} \mathrm{CN}$.

The lowest energy absorption maxima for all four complexes do not vary significantly, which is expected since the MLCT transition should occur from the $\mathrm{Re}^{\mathrm{I}}$ metal center to the $\pi^{*}$ orbitals in the 2,2'-bipyridine. The complexes $\mathbf{1}$ and $\mathbf{4}$ exhibit MLCT bands broader and slightly red-shifted in relation to those for the complexes $\mathbf{2}$ and 3. This observation can be explained by the stronger $\pi$ back donation in the complexes $\mathbf{2}$ and $\mathbf{3}$, in which the pyrazine ring in the former and the resonant $4,4^{\prime}$ 'bipyridyl ligand in the latter act as better electron acceptors than the single pyridyl ring in complexes $\mathbf{1}$ and $\mathbf{4}$.

Data from TD-DFT calculations corroborate with these conclusions. The most important configurations of the states associated to the low energy absorption bands are listed in the Table 1. The isosurface plots of the frontier orbitals involved in these transitions are shown in Figure 2. 
For complexes $\mathbf{1}$ and $\mathbf{4}$, the ancillary ligands (py and bpa) have a negligible influence on the low energy electronic transitions, which involve basically orbitals centered on the metal and in the 2,2-bipyridine ligand. On the other hand, for the complexes $\mathbf{2}$ and $\mathbf{3}$, one can observe a strong influence of pyrazine and 4,4'-bipyridine on the frontier orbitals.

In complex 2, the electron density in the HOMO (highest occupied molecular orbital) is spread between the $\mathrm{d}$ orbitals of $\mathrm{Re}^{\mathrm{I}}$ and the pyrazine rings, with a reasonable contribution of the non-ligand electron pair in the free $\mathrm{N}$ atom (see Figure 2). As for the complexes $\mathbf{1}$ and $\mathbf{4}$, the LUMO (lowest unoccupied molecular orbital) in $\mathbf{2}$ is centered in the $\pi^{*}$ orbitals of 2,2-bpy, but the LUMO+1 is formed almost exclusively by $\pi^{*}$ orbitals of pyrazine. As listed in the Table 1, the low energy absorption band is a complex mixture of several transitions involving more internal orbitals, such as HOMO-4, but it is noteworthy to note the contribution of LUMO+1. Thus, it can be concluded that for complex $\mathbf{2}$ the low energy absorption band is a combination of charge transfers from the metal center to both, pyrazine and 2,2-bpy, with some contribution of $n-\pi *$ internal transition of pyrazine, $\mathrm{IL}_{(\mathrm{pz})}$.

The contribution of the ancillary ligand to the lowest energy transitions reaches a maximum in the complex $\mathbf{3}$, in which the LUMO is not centered at the $\pi^{*}$ orbitals of 2,2-bpy, but is composed by $\pi^{*}$ orbitals of 4,4-bpy.
The electronic transition with the highest oscillator strength is $S_{0} \rightarrow S_{3}$, corresponding to a charge transfer from the metal to 2,2-bpy $(88.2 \%$ ) and to 4,4-bpy $(11.8 \%)$. This result agrees very well with ns-transient absorption studies performed by Meyer and co-workers ${ }^{24}$ in which an intramolecular electron transfer from 2,2-bpy to 4,4-bpy was identified after MLCT excitation of $f a c-\left[\operatorname{Re}^{\mathrm{I}}(\mathrm{CO})_{3}(2,2-\mathrm{bpy})(4,4-\mathrm{bpy})\right]^{+}$in the presence of hydroquinone (equation 4). As the LUMO is composed by $\pi^{*}$ orbitals of 4,4-bpy, the photoexcited electron transfer should increase the basicity of this ligand, influencing directly the proton transfer.

$$
\begin{aligned}
f a c-\left[\operatorname{Re}^{\mathrm{I}}(\mathrm{CO})_{3}\left(2,2-\text { bpy }^{\bullet}\right)(4,4-b p y)\right]^{+} \rightarrow \\
f a c-\left[\operatorname{Re}^{\mathrm{I}}(\mathrm{CO})_{3}(2,2-\text { bpy })\left(4,4-\mathrm{bpy} \mathbf{y}^{\bullet}\right)\right]^{+}
\end{aligned}
$$

Further information on the thermodynamics of possible MLCT-state PCET can be obtained from electrochemical and luminescence data. The first oxidation and reduction electrochemical potentials of the investigated complexes are listed in Table 2, along with their luminescent properties in acetonitrile at room temperature. The values are in good agreement with values reported in the literature. ${ }^{36-38}$ The first oxidation peak for the complexes are non-reversible and ascribed to $\mathrm{Re}^{\mathrm{I}} / \mathrm{Re}^{\mathrm{II}}$ oxidation, being experimentally similar for all complexes. At negative potentials the redox activity is dominated by the reduction of pyridyl ligands.

\begin{tabular}{|c|c|c|c|c|c|}
\hline Complex & State & $\begin{array}{l}\text { Main configurations } \\
\quad(\text { weights / \% })^{\mathrm{a}}\end{array}$ & $f$ & $\lambda / \mathrm{nm}$ & Character \\
\hline \multirow[t]{2}{*}{1} & $\mathrm{~S}_{1}$ & $\mathrm{H} \rightarrow \mathrm{L}$ & 0.0036 & 423.8 & $\operatorname{MLCT}_{\mathrm{d}(\mathrm{Re}) \rightarrow \varpi^{*}(2,2 \text {-bpy })}$ \\
\hline & $\mathrm{S}_{3}$ & $\begin{array}{l}\mathrm{H}-1 \rightarrow \mathrm{L}(29) \\
\mathrm{H}-2 \rightarrow \mathrm{L}(71)\end{array}$ & 0.072 & 385.7 & $\mathrm{MLCT}_{\mathrm{d}(\mathrm{Re}) \rightarrow \sigma^{*}(2,2 \text {-bpy })}$ \\
\hline \multirow[t]{2}{*}{2} & $\mathrm{~S}_{1}$ & $\begin{array}{c}\mathrm{H} \rightarrow \mathrm{L}(4.8) \\
\mathrm{H} \rightarrow \mathrm{L}+1(41.2) \\
\mathrm{H}-2 \rightarrow \mathrm{L}+1(2.9) \\
\mathrm{H}-4 \rightarrow \mathrm{L}+1(51.1)\end{array}$ & 0.0023 & 316.1 & $\begin{array}{c}\mathrm{IL}_{(\mathrm{pz})} \\
\operatorname{MLCT}_{\mathrm{d}(\mathrm{Re}) \rightarrow \varpi^{*}(\mathrm{pz})} \\
\operatorname{MLCT}_{\mathrm{d}(\mathrm{Re}) \rightarrow \varpi^{*}(2,2-\mathrm{bpy})}\end{array}$ \\
\hline & $\mathrm{S}_{5}$ & $\begin{array}{c}\mathrm{H}-1 \rightarrow \mathrm{L}(7.3) \\
\mathrm{H}-1 \rightarrow \mathrm{L}+1(2.3) \\
\mathrm{H}-1 \rightarrow \mathrm{L}+2(3) \\
\mathrm{H}-3 \rightarrow \mathrm{L}(87.5)\end{array}$ & 0.3005 & 288.1 & $\mathrm{IL}_{(2,2 \text {-bpy })}$ \\
\hline \multirow[t]{2}{*}{3} & $\mathrm{~S}_{1}$ & $\mathrm{H} \rightarrow \mathrm{L}$ & 0.0044 & 421.0 & $\operatorname{MLCT}_{\mathrm{d}(\mathrm{Re}) \rightarrow \varpi^{*}(4,4-\text { bpy })}$ \\
\hline & $\mathrm{S}_{4}$ & $\begin{array}{c}\mathrm{H} \rightarrow \mathrm{L}+1(88.2) \\
\mathrm{H}-1 \rightarrow \mathrm{L}(6.4) \\
\mathrm{H}-2 \rightarrow \mathrm{L}(5.4) \\
\end{array}$ & 0.24 & 398.9 & $\begin{array}{l}\operatorname{MLCT}_{\mathrm{d}(\mathrm{Re}) \rightarrow \varpi^{*}(2,2-\text {-bpy })} \\
\operatorname{MLCT}_{\mathrm{d}(\mathrm{Re}) \rightarrow \Phi^{*}(4,4-\text { bpy })}\end{array}$ \\
\hline \multirow[t]{2}{*}{4} & $\mathrm{~S}_{1}$ & $\begin{array}{c}\mathrm{H} \rightarrow \mathrm{L}(14.6) \\
\mathrm{H}-1 \rightarrow \mathrm{L}(85.4)\end{array}$ & 0.0028 & 370.3 & $\operatorname{MLCT}_{\mathrm{d}(\mathrm{Re}) \rightarrow \varpi^{*}(2,2 \text {-bpy })}$ \\
\hline & $\mathrm{S}_{2}$ & $\begin{array}{l}\mathrm{H} \rightarrow \mathrm{L}(79.2) \\
\mathrm{H}-1 \rightarrow \mathrm{L}(14) \\
\mathrm{H}-2 \rightarrow \mathrm{L}(6.8)\end{array}$ & 0.0718 & 363.5 & $\operatorname{MLCT}_{\mathrm{d}(\mathrm{Re}) \rightarrow \Phi^{*}(2,2 \text {-bpy })}$ \\
\hline
\end{tabular}

Table 1. Selected energy electronic transitions for $f a c-\left[\operatorname{Re}(\mathrm{CO})_{3}(2,2 \text {-bpy })(\mathrm{L})\right]^{+}$with their respective oscillator strengths $(f)$ and associated wavelengths $(\lambda)$

${ }^{\mathrm{a} H}$ : HOMO; L: LUMO. 


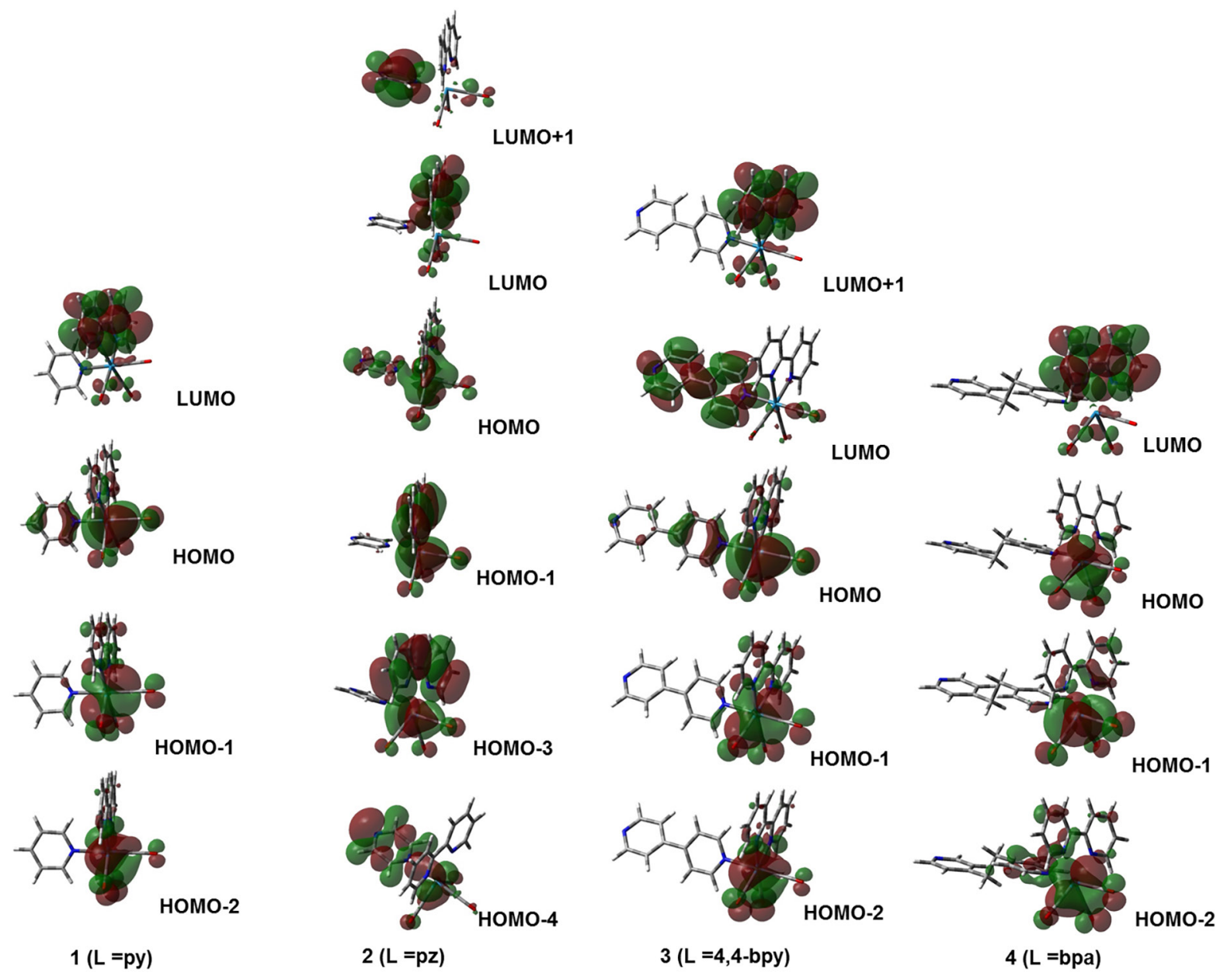

Figure 2. Isosurface plots of selected frontier orbitals of complexes 1-4.

Table 2. First oxidation and reduction electrochemical potentials $v s$. $\mathrm{Fc}^{+} / \mathrm{Fc}$ and luminescent properties of $\left.f a c-[\operatorname{Re}(\mathrm{CO}))_{3}(2,2-\mathrm{bpy})(\mathrm{L})\right]^{+}$in $\mathrm{CH}_{3} \mathrm{CN}$ at $298 \mathrm{~K}$

\begin{tabular}{lccccccc}
\hline $\mathrm{L}$ & $\mathrm{E}_{\mathrm{ox}} / \mathrm{V}$ & $\mathrm{E}_{\mathrm{red}} / \mathrm{V}$ & $\lambda_{\mathrm{em}} \max / \mathrm{nm}$ & $\varphi$ & $\tau_{0} / \mathrm{ns}$ & $\mathrm{k}_{\mathrm{r}} /\left(10^{5} \mathrm{~s}^{-1}\right)$ & $\mathrm{E}_{\mathrm{red}}^{*} / \mathrm{V}$ \\
\hline py (1) & 1.38 & -1.59 & $553(2.24 \mathrm{eV})$ & 0.060 & 249 & 2.41 & 0.65 \\
$\operatorname{pz~(2)}$ & 1.35 & -1.54 & $545(2.27 \mathrm{eV})$ & 0.097 & 418 & 2.32 & 0.73 \\
4,4-bpy (3) & 1.34 & -1.60 & $553(2.24 \mathrm{eV})$ & 0.052 & 250 & 2.00 & 0.64 \\
$\operatorname{ppa}(\mathbf{4})$ & 1.31 & -1.60 & $554(2.24 \mathrm{eV})$ & 0.057 & 210 & 2.86 & 0.64 \\
\hline
\end{tabular}

$\mathrm{k}_{\mathrm{r}}=\phi / \tau_{0}$ : radiative decay rate constant; $\mathrm{E}_{\text {red }}^{*}$ : reduction potentials of the ${ }^{3} \mathrm{MLCT}$-excited complexes $v s$. $\mathrm{Fc}^{+} / \mathrm{Fc}$.

All species exhibit luminescence in acetonitrile at room temperature. In the emission spectra (Figure S1, Supplementary Information), one can observe a broad emission band, with very close emission maxima. For the complex $\mathbf{2}$, the emission peak is slightly blue-shifted in relation to the other complexes and, as a result, its emission quantum yield as well as emission lifetime are higher, as predicted by the energy gap law..$^{27,39}$ Radiative decay rate constants calculated as $\mathrm{k}_{\mathrm{r}}=\varphi / \tau_{0}$ vary from 2.00 to $2.86 \times 10^{5} \mathrm{~s}^{-1}$ and follow the order $\mathbf{3}<\mathbf{1} \cong \mathbf{2}<\mathbf{4}$. The reduction potentials of the ${ }^{3}$ MLCT-excited complexes
$\left(\mathrm{E}^{*}{ }_{\text {red }} v s . \mathrm{Fc}^{+} / \mathrm{Fc}\right)$ can be estimated by adding the energy of MLCT state (emission maxima in $\mathrm{eV}$ ) to the respective ground-state one-electron reduction potentials. ${ }^{40}$ It can be concluded from electrochemical and luminescence data that the driving force for the electron transfer to the ${ }^{3}$ MLCT-excited complexes investigated here are very similar, being ca. $0.09 \mathrm{eV}$ more positive for the complex 2 . Given that the hydroquinone one electron reduction, $\mathrm{E}^{\circ}\left(\mathrm{H}_{2} \mathrm{Q}^{+} / \mathrm{H}_{2} \mathrm{Q}\right)$ is $1.10 \mathrm{~V} v s$. NHE or $0.47 \mathrm{~V} v s$. $\mathrm{Fc}^{+} / \mathrm{Fc}$, the driving force for the photoinduced electron transfer (ET) from hydroquinone to the $\mathrm{Re}^{\mathrm{I}}$ complexes are ca. $0.2-0.3 \mathrm{eV}$. 
If a proton is simultaneously released to the medium or to the complex, the driving force is then increased by $0.06 \mathrm{eV}$, corresponding to the difference between the reduction potentials of the one electron transfer and the concerted electron-proton transfer by hydroquinone $\left(\mathrm{E}^{\mathrm{o}}\left[\mathrm{HQ}^{+\bullet} / \mathrm{H}_{2} \mathrm{Q}\right]=0.41\right.$ vs. $\left.\mathrm{Fc}^{+} / \mathrm{Fc}\right)$.

\section{Quenching studies}

As shown in the Figure 3 for the complex 4 , the ${ }^{3}$ MLCT luminescence intensity and lifetime of the $\mathrm{Re}^{\mathrm{I}}$ complexes are quenched by hydroquinone in net acetonitrile and in $1: 1 \mathrm{CH}_{3} \mathrm{CN} / \mathrm{H}_{2} \mathrm{O}$ mixture at $298 \mathrm{~K}$. Similar behavior is observed for the complexes 1-3 (Figures S2, S3 and S4 of Supplementary Information, respectively). Moreover, the quenching process for the different $\mathrm{Re}^{\mathrm{I}}$ complexes can be fitted to the Stern-Volmer kinetics model (equation 5), in which $S_{0}, \tau_{0}$ and $S, \tau$ are the corresponding emission intensities (calculated as the area under the spectra) and lifetimes observed, respectively, in the absence and presence of different hydroquinone concentrations $\left(\left[\mathrm{H}_{2} \mathrm{Q}\right]\right)$ and $\mathrm{k}_{\mathrm{q}}$ is the quenching rate constant. The experimental fits obtained for all complexes in different media are shown in Figure 4. The Stern-Volmer kinetic behavior indicates that the dynamic mechanism is the main reaction pathway in the experimental conditions employed, with none (or very small) influence of the ground state preassociation step through a hydrogen bonding between the hydroquinone and the complexes 2-4, followed by a photoinduced EPT. Taking the acidity constants for the free protonated ligands $\left(\mathrm{pKa}=0.37,4.4,5.2\right.$, respectively, for $\mathrm{pz}, 4,4^{\prime}$-bpy and $\mathrm{bpa})^{41,42}$ and for the hydroquinone $(\mathrm{pKa}=10.8),{ }^{43}$ the PT-ET pathway can be ruled out. Therefore, it can be concluded that the major PCET mechanism for the excited state quenching of the investigated $\mathrm{Re}^{\mathrm{I}}$ complex by hydroquinone is the ET-PT pathway.

$\frac{\mathrm{S}_{0}}{\mathrm{~S}}=\frac{\tau_{0}}{\tau}=1+\mathrm{k}_{\mathrm{q}} \tau_{0}\left[\mathrm{H}_{2} \mathrm{Q}\right]$
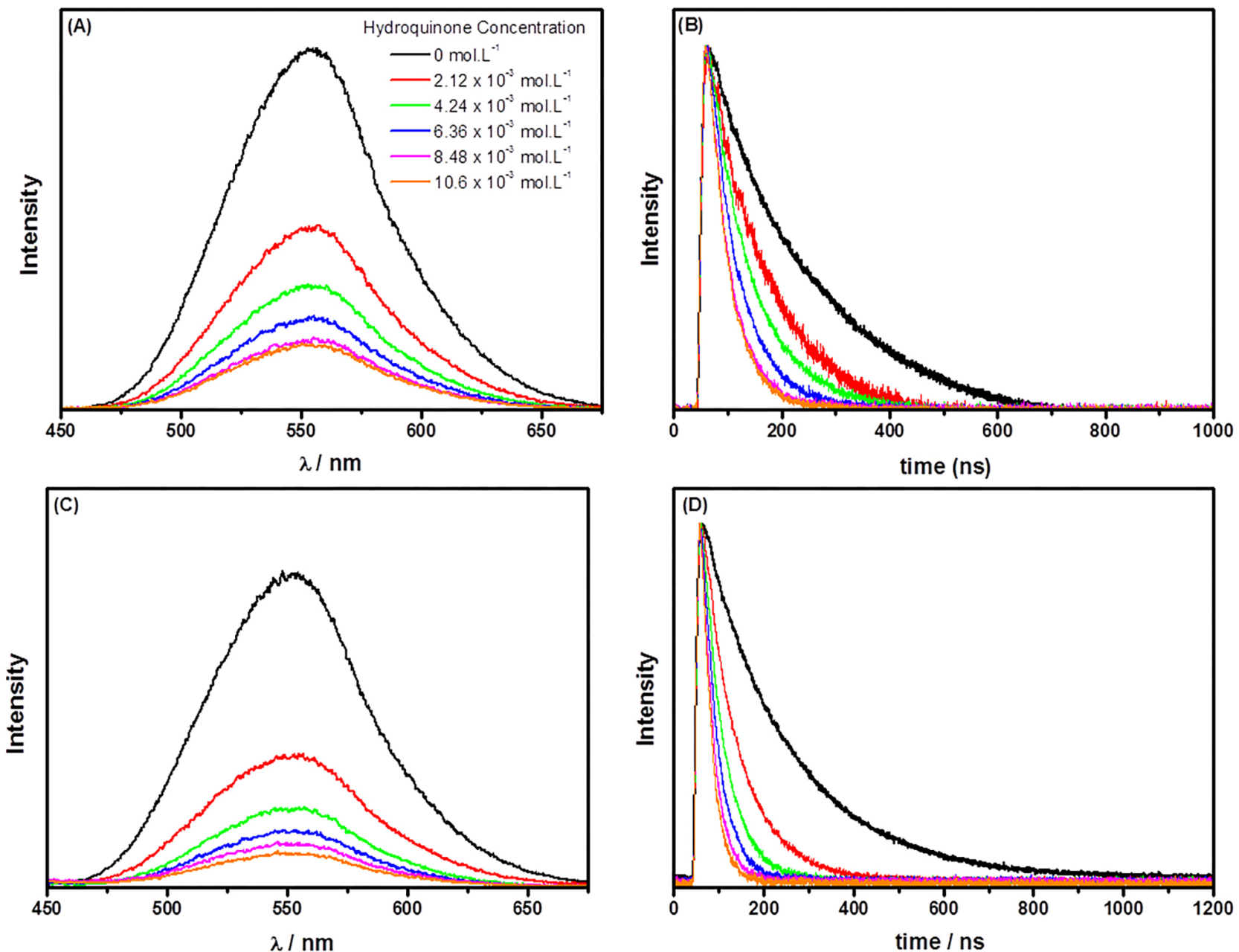

Figure 3. Emission intensity and lifetime changes for complex 4 in acetonitrile (A, B) and 1:1 in $\mathrm{CH}_{3} \mathrm{CN}: \mathrm{H}_{2} \mathrm{O}$ solutions (C, D) as a function of hydroquinone concentration. For (A) and (C), $\lambda_{\mathrm{exc}}=350 \mathrm{~nm}$; for (B) and (D), $\lambda_{\mathrm{exc}}=355 \mathrm{~nm}, \lambda_{\text {probe }}=550 \mathrm{~nm}$. 

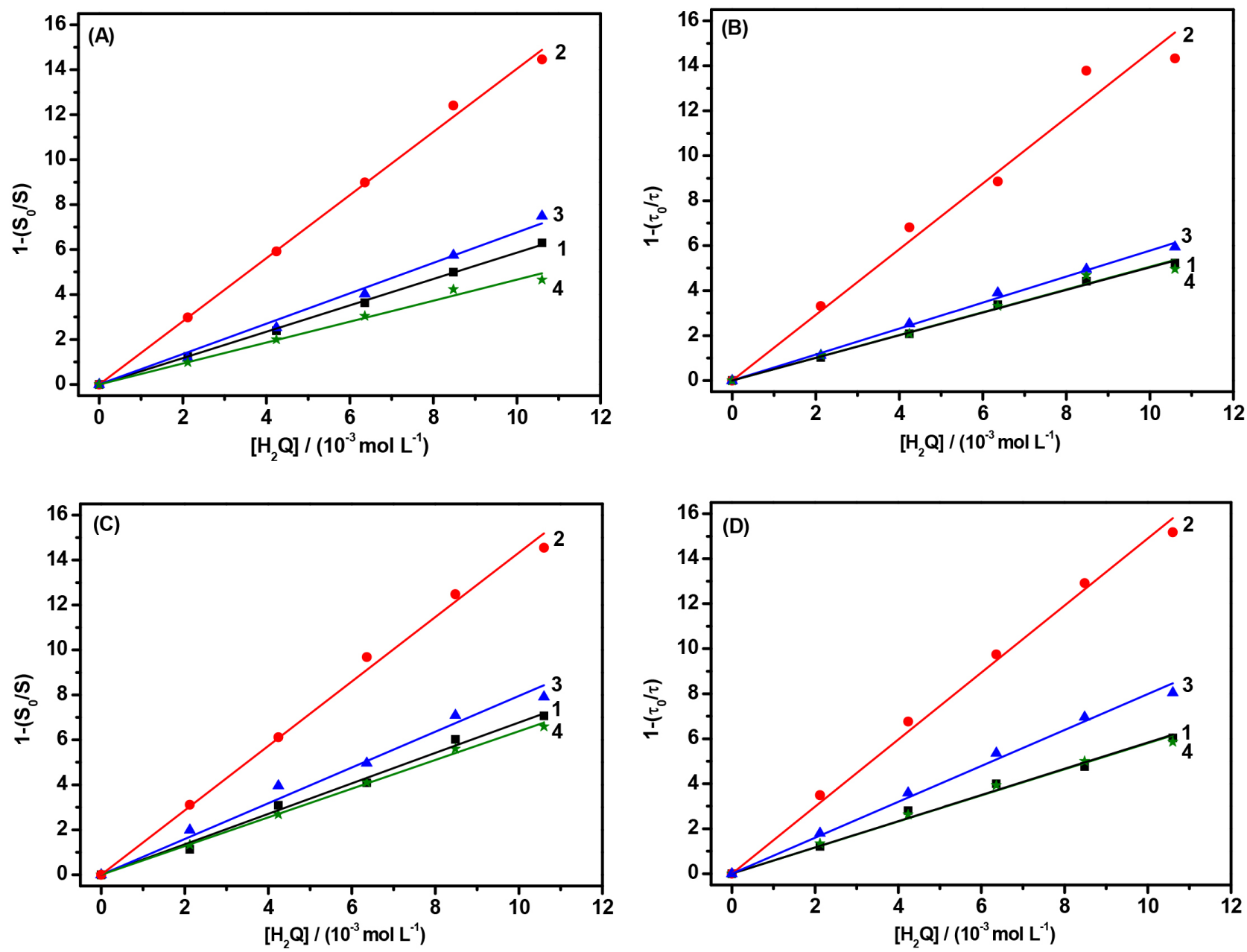

Figure 4. Stern-Volmer plots in $\mathrm{CH}_{3} \mathrm{CN}$ (A, B) and in 1:1 $\mathrm{CH}_{3} \mathrm{CN} / \mathrm{H}_{2} \mathrm{O}(\mathrm{C}, \mathrm{D})$ at $298 \mathrm{~K}$ for $\mathbf{1}$ (black squares), 2 (red circles), 3 (blue triangles) and 4 (green star), obtained from steady-state measurements $(\mathrm{A}, \mathrm{C})$ or by lifetime measurements $(\mathrm{B}, \mathrm{D})$.

The quenching rate constants $\left(\mathrm{k}_{\mathrm{q}}\right)$ obtained from the linear fittings from both, emission intensities and lifetimes, are summarized in the Table 3 . The complex 2 exhibits the higher $\mathrm{k}_{\mathrm{q}}$ in acetonitrile, followed by complex $\mathbf{3}$. For comparison, the values obtained for $\mathbf{3}$ in $\mathrm{CH}_{3} \mathrm{CN}$ are slightly above to $(1.8 \pm 0.2) \times 10^{9} \mathrm{~L} \mathrm{~mol}^{-1} \mathrm{~s}^{-1}$ reported by Stewart et $a l .{ }^{24}$ Considering the values obtained by lifetime measurements, the species $\mathbf{1}$ and $\mathbf{4}$ show experimentally similar quenching rate constants, being the lowest ones among the investigated series. As the medium is changed from acetonitrile to $1: 1 \mathrm{CH}_{3} \mathrm{CN} / \mathrm{H}_{2} \mathrm{O}$ mixture, one can observe an increase in all rate constants. This behavior can be explained by the role of water as proton acceptor following the electron transfer from hydroquinone to the electronic excited $\operatorname{Re}^{\mathrm{I}}$ complexes. As one electron is transferred from $\mathrm{H}_{2} \mathrm{Q}$ to the complexes, the protonated semiquinone radical $\left(\mathrm{H}_{2} \mathrm{Q}^{*+} \text {, } \mathrm{pKa}=-1\right)^{6}$ can release a proton to the water molecules. When only acetonitrile $(\mathrm{pKa}=-4.5)$ is used as solvent, the proton release to the medium is thermodynamically non-spontaneous. It is also interesting to observe how closer are the values of $\mathrm{k}_{\mathrm{q}}$ for the different complexes in 1:1 $\mathrm{CH}_{3} \mathrm{CN} / \mathrm{H}_{2} \mathrm{O}$ in comparison to those obtained in acetonitrile, indicating that as a proton acceptor is added to the medium the observed rate constant should be close to the diffusion limit.

It is noteworthy to observe that the enhancement of the magnitude for the quenching rate constant due to addition of $\mathrm{H}_{2} \mathrm{O}$ is different for the complexes investigated and highlights the influence of the ancillary ligand on the PCET process. While for the complex $\mathbf{2}, \mathrm{k}_{\mathrm{q}}$ is increased only $12 \%$ as water is introduced in the reaction medium, this enhancement is of $32 \%$ for $\mathbf{3}, 50 \%$ for $\mathbf{1}$ and $57 \%$ for 2 (percentage increments calculated as average of the variations observed for the intensity and lifetime measurements). In complex $\mathbf{1}$, there is no protonable site, thus the proton transfer step in acetonitrile strongly decreases the observed rate constant. As a base (water) is introduced to the medium, the energy barrier for the proton transfer is diminished and a significant increase in the observed rate constant is observed. Surprisingly, for 
Table 3. Stern-Volmer constants $\left(\mathrm{K}_{\mathrm{SV}}=\mathrm{k}_{\mathrm{q}} \tau_{0}\right)$ and the respective quenching rate constant $\left(\mathrm{k}_{\mathrm{q}}\right)$ for complexes 1-4 in the presence of hydroquinone and in different media at $298 \mathrm{~K}$

\begin{tabular}{|c|c|c|c|c|c|c|c|c|c|c|}
\hline \multirow{3}{*}{$\mathrm{L}$} & \multicolumn{5}{|c|}{$\mathrm{CH}_{3} \mathrm{CN}$} & \multicolumn{5}{|c|}{$1: 1 \mathrm{CH}_{3} \mathrm{CN} / \mathrm{H}_{2} \mathrm{O}$} \\
\hline & \multirow[t]{2}{*}{$\tau_{0} / \mathrm{ns}$} & \multicolumn{2}{|c|}{ Intensity } & \multicolumn{2}{|c|}{ Lifetime } & \multirow[t]{2}{*}{$\tau_{0} / \mathrm{ns}$} & \multicolumn{2}{|c|}{ Intensity } & \multicolumn{2}{|c|}{ Lifetime } \\
\hline & & $\mathrm{K}_{\mathrm{sV}} / \mathrm{M}^{-1}$ & $\mathrm{k}_{\mathrm{q}} /\left(10^{9} \mathrm{M}^{-1} \mathrm{~s}^{-1}\right)$ & $\mathrm{K}_{\mathrm{sV}} / \mathrm{M}^{-1}$ & $\mathrm{k}_{\mathrm{q}} /\left(10^{9} \mathrm{M}^{-1} \mathrm{~s}^{-1}\right)$ & & $\mathrm{K}_{\mathrm{sv}} / \mathrm{M}^{-1}$ & $\mathrm{k}_{\mathrm{q}} /\left(10^{9} \mathrm{M}^{-1} \mathrm{~s}^{-1}\right)$ & $\mathrm{K}_{\mathrm{SV}} / \mathrm{M}^{-1}$ & $\mathrm{k}_{\mathrm{q}} /\left(10^{9} \mathrm{M}^{-1} \mathrm{~s}^{-1}\right)$ \\
\hline py (1) & 249 & $586 \pm 6$ & $2.36 \pm 0.03$ & $506 \pm 5$ & $2.03 \pm 0.02$ & 190 & $670 \pm 6$ & $3.53 \pm 0.03$ & $583 \pm 5$ & $3.07 \pm 0.02$ \\
\hline $\mathrm{pz}(\mathbf{2})$ & 418 & $1404 \pm 8$ & $3.36 \pm 0.03$ & $1461 \pm 8$ & $3.49 \pm 0.02$ & 380 & $1433 \pm 9$ & $3.77 \pm 0.03$ & $1490 \pm 6$ & $3.92 \pm 0.02$ \\
\hline 4,4-bpy (3) & 250 & $676 \pm 7$ & $2.70 \pm 0.03$ & $625 \pm 6$ & $2.50 \pm 0.02$ & 232 & $795 \pm 7$ & $3.43 \pm 0.03$ & $798 \pm 6$ & $3.44 \pm 0.02$ \\
\hline bpa (4) & 250 & $505 \pm 5$ & $2.02 \pm 0.02$ & $504 \pm 5$ & $2.01 \pm 0.02$ & 192 & $638 \pm 6$ & $3.32 \pm 0.03$ & $580 \pm 6$ & $3.02 \pm 0.03$ \\
\hline
\end{tabular}

the complex 4 , a very similar behavior occurs. It means the proton transfer for the non-coordinated nitrogen atom of the bpa ligand should not play an effective role on photoinduced PCET process. Different from the observed for $4,4^{\prime}$-bpy and for pyrazine, the non-coordinated pyridyl ring in bpa has negligible electronic interaction with the metal center in $\mathbf{4}$, thus MLCT excitation should not produce any substantial changes in its basicity.

For complexes $\mathbf{2}$ and $\mathbf{3}$, much smaller enhancements in $\mathrm{k}_{\mathrm{q}}$ are observed as the reaction medium is changed from $\mathrm{CH}_{3} \mathrm{CN}$ to $1: 1 \mathrm{CH}_{3} \mathrm{CN} / \mathrm{H}_{2} \mathrm{O}$, which indicates that the proton transfer for these $\mathrm{Re}^{\mathrm{I}}$ complexes has smaller energy barriers in bare acetonitrile than that for $\mathbf{4}$. In complexes $\mathbf{2}$ and $\mathbf{3}$, TDDFT calculations have shown that MLCT excitation leads to population of LUMO and LUMO+1. In $\mathbf{3}$, the LUMO is centered in the 4,4'-bpy ligand, which is the final electron acceptor as shown before. ${ }^{24}$ Thus, MLCT excitation of $\mathbf{3}$ improves the basicity of 4,4'-bpy and further protonation by $\mathrm{H}_{2} \mathrm{Q}^{++}$leads to stabilization of the reaction products. In $\mathbf{2}$, the LUMO is centered in the 2,2'-bipyridyl ligand, but the LUMO+1 is centered in the pyrazine ligand. The energy difference for these states is estimated to be $0.28 \mathrm{eV}$ (for $\mathbf{3}$, the energy gap between LUMO and LUMO+1 is $0.41 \mathrm{eV}$ ).
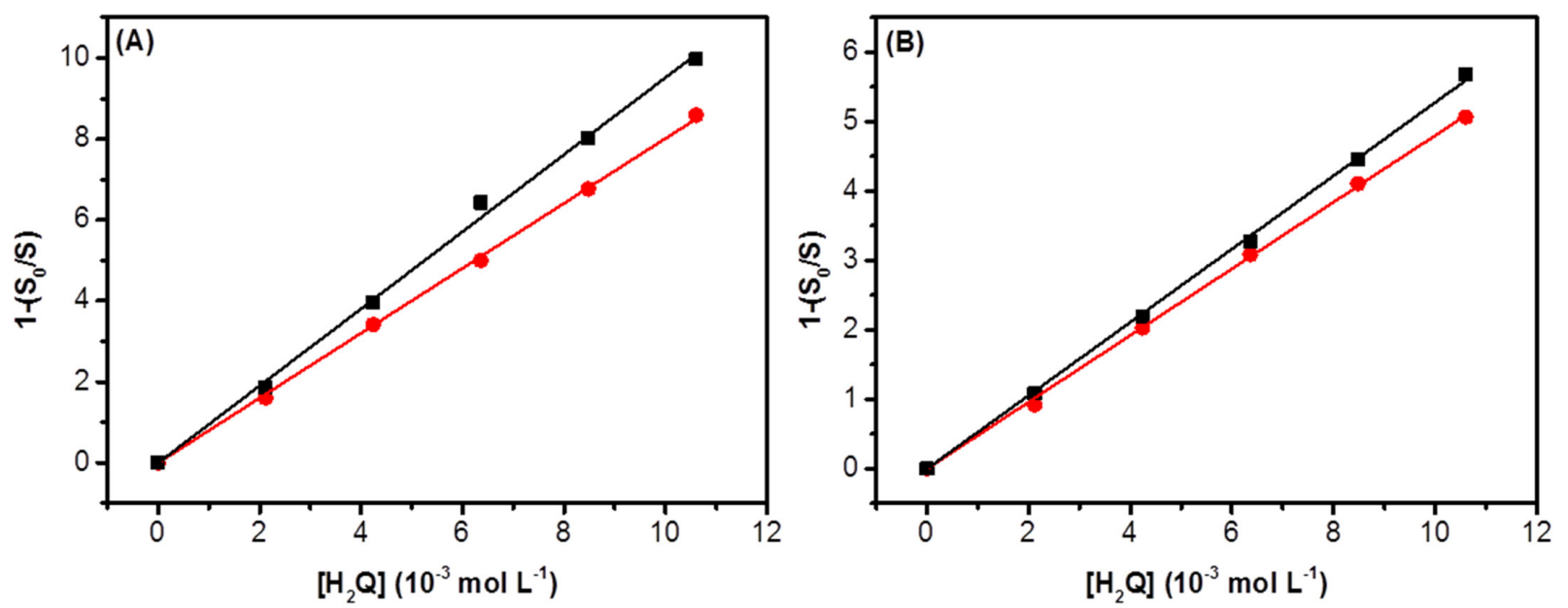

Figure 5. Stern-Volmer plots for the luminescence quenching of $\mathbf{2}$ (A) and $\mathbf{3}$ (B) by hydroquinone in $3: 1 \mathrm{CH}_{3} \mathrm{CN} / \mathrm{H}_{2} \mathrm{O}$ (black squares) and in $3: 1 \mathrm{CH}_{3} \mathrm{CN} / \mathrm{D}_{2} \mathrm{O}$ (red circles).

Thus, it can be expected that MLCT excitation on 2 also increases the basicity of the coordinated pyrazine ligand, leading to an increase in the driving force for the proton transfer, following the electron transfer.

It is also interesting to note that the quenching rate constant for $\mathbf{2}$ in $\mathrm{CH}_{3} \mathrm{CN}$ is higher than that for $\mathbf{3}$. To further investigate the origin of this difference, it was determined the quenching rate constants for these complexes by hydroquinone in 3:1 $\mathrm{CH}_{3} \mathrm{CN} / \mathrm{H}_{2} \mathrm{O}$ and in $\mathrm{CH}_{3} \mathrm{CN} / \mathrm{D}_{2} \mathrm{O}$ (Figure 5) in such a way that the KIE can be obtained. For 2, a KIE of $1.2 \pm 0.1$ was determined, while for $\mathbf{3}$, it was found a KIE of $1.1 \pm 0.1$, in accordance to the values reported by Steward et al. ${ }^{24}\left(\mathrm{KIE}=1.1\right.$ in $1: 1 \mathrm{CH}_{3} \mathrm{CN} / \mathrm{X}_{2} \mathrm{O}$, $\mathrm{X}=\mathrm{H}$ or $\mathrm{D}$ ). For reference, the KIE found for $\mathbf{1}$ determined under similar experimental conditions was $1.0 \pm 0.1$.

The experimental variations make difficult to take decisive conclusions on the isotope effect. As the ET-PT is likely the major pathway in the quenching reaction, it is not expected significant isotope effects, as previous discussed by Mayer and co-workers. ${ }^{44}$ Nevertheless, the slightly superior KIE value found for $\mathbf{2}$ may indicate a higher contribution of concerted electron-proton transfer (EPT) pathway for this complex in relation to $\mathbf{3}$ and $\mathbf{4}$, since 
the PT-ET pathway is thermodynamically improbable. It is also important to highlight that the absence of significant KIEs is not an argument against EPT, since this pathway can involve vibrationally excited species. ${ }^{10,44}$

An additional reaction pathway that could be considered is the initial proton transfer after MLCT excitation of 2 (*PT-ET), followed by reduction of the protonated complex, but in this case, a much higher KIE is expected. Moreover, the determined KIE values do not justify by themselves the differences of the $\mathrm{k}_{\mathrm{q}}$ values between $\mathbf{2}$ and $\mathbf{3}$ in bare acetonitrile. Thus, it can be speculated that different solvation effects related to the change ancillary ligand in $\mathrm{Re}^{\mathrm{I}}$ complexes can lead to different reorganization energies for the electron transfer step, as predicted for out sphere electron transfer reactions. ${ }^{45-47}$

The results evidence that the luminescence quenching of $\mathrm{Re}^{\mathrm{I}}$ polypyridyl complexes by hydroquinone occurs mainly by reductive electron transfer, followed by proton transfer to complex or to the medium when an appropriate base is present. In the investigated series, higher quenching rate constants were found for complexes $\mathbf{2}$ and $\mathbf{3}$ in acetonitrile, which can be explained by a lower energy barrier for the electron transfer in these complexes and also by the increased basicity of coordinated pyrazine and 4,4-bipyridyl after MLCT excitation. The small isotope effects indicate that the electron transfer is the rate-limiting step, thus the changes in the nature of MLCT excited state in $\mathbf{2}$ and $\mathbf{3}$ should also affect positively the electron transfer step. Nevertheless, the concerted electron-proton transfer pathway seems to play a hole at high hydroquinone concentrations.

\section{Conclusion}

In the present work the influence of the ancillary ligand on the luminescence quenching of $f a c-\left[\operatorname{Re}(\mathrm{CO})_{3}(\mathrm{bpy})(\mathrm{L})\right]^{+}$ by hydroquinone was investigated ( $\mathrm{L}=\mathrm{py}, \mathrm{pz}, 4,4$ '-bpy and bpa). In this series the redox potentials and the MLCT energies do not vary significantly and, then, it was expected to identify the influence of the protonatable site on the photo-induced PCET chemistry. The results found showed that the major quenching reaction pathway is the reduction of the $\mathrm{Re}^{\mathrm{I}}$ complexes by hydroquinone by single electron transfer, followed by proton transfer to the protonatable site in the ancillary ligand or to a base present in the medium. In $1: 1 \mathrm{CH}_{3} \mathrm{CN} / \mathrm{H}_{2} \mathrm{O}$, the observed quenching rate constants are very similar as the water molecules work as proton acceptors and the increased polarity favors the electron transfer step. In bare acetonitrile, complex 2 exhibits the higher $\mathrm{k}_{\mathrm{q}}$ followed by complex 3 . TD-DFT calculations suggest that for these complexes MLCT excitation should lead to an increase in the basicity of the non-coordinate nitrogen atom in the ancillary ligand via intramolecular electron transfer. As a result the driving force for the proton transfer increases. The low H/D kinetic isotope effect observed for the complexes reveals that the rate limiting step involves the electron transfer from $\mathrm{H}_{2} \mathrm{Q}$ to the $\mathrm{Re}^{\mathrm{I}}$ complexes, but the concerted proton-electron transfer (EPT) pathway seems to play a hole at high hydroquinone concentrations, especially for complexes $\mathbf{2}$ and $\mathbf{3}$.

\section{Supplementary Information}

Supplementary information (emission spectra of the complexes, quenching studies data, comparisons between the experimental and the theoretical absorption spectra) is available free of charge at http://jbcs.sbq.org.br as a PDF file.

\section{Acknowledgments}

This work was supported by Fundacão de Amparo à Pesquisa do Estado de Minas Gerais (FAPEMIG), Conselho Nacional de Desenvolvimento Científico e Tecnológico (CNPq) and Coordenação de Aperfeiçoamento de Pessoal de Nível Superior (CAPES). The authors are thankful to the Grupo de Materiais Inorgânicos do Triângulo (GMIT), a research group supported by FAPEMIG (APQ-00330-14). The authors are also thankful to the Laboratory of NMR (Instituto de Química, Universidade Federal de Goias (IQUFG), MCT/FINEP/CT-INFRA - PROINFRA - 01/2004) for the NMR analyses.

\section{References}

1. Nunes, G. S.; Alexiou, A. D. P.; Araki, K.; Formiga, A. L. B.; Rocha, R. C.; Toma, H. E.; Eur. J. Inorg. Chem. 2006, 7, 1487.

2. Gagliardi, C. J.; Vannucci, A. K.; Concepcion, J. J.; Chen, Z.; Meyer, T. J.; Energy Environ. Sci. 2012, 5, 7704.

3. Buldt, L. A.; Prescimone, A.; Neuburger, M.; Wenger, O. S.; Eur. J. Inorg. Chem. 2015, 28, 4666.

4. Manbeck, G. F.; Fujita, E.; Concepcion, J. J.; J. Am. Chem. Soc. 2016, 138, 11536.

5. Meyer, T. J.; Huynh, M. H. V.; Thorp, H. H.; Angew. Chem. 2007, 46, 5284.

6. Weinberg, D. R.; Gagliardi, C. J.; Hull, J. F.; Murphy, C. F.; Kent, C. A.; Westlake, B. C.; Paul, A.; Ess, D. H.; McCafferty, D. G.; Meyer, T. J.; Chem. Rev. 2012, 112, 7, 4016.

7. Song, W. J.; Chen, Z. F.; Brennaman, M. K.; Concepcion, J. J.; Patrocinio, A. O. T.; Murakami Iha, N. Y.; Meyer, T. J.; Pure Appl. Chem. 2011, 83, 749.

8. Huynh, M. H. V.; Meyer, T. J.; Chem. Rev. 2007, 107, 5004. 
9. Wenger, O. S.; Acc. Chem. Res. 2013, 46, 1517.

10. Wenger, O. S.; Coord. Chem. Rev. 2015, 282, 150.

11. Gagliardi, C. J.; Westlake, B. C.; Kent, C. A.; Paul, J. J.; Papanikolas, J. M.; Meyer, T. J.; Coord. Chem. Rev. 2010, 254, 2459.

12. Rocha, R. C.; Rein, F. N.; Toma, H. E.; J. Braz. Chem. Soc. 2001, 12, 234.

13. Liu, F.; Cardolaccia, T.; Hornstein, B. J.; Schoonover, J. R.; Meyer, T. J.; J. Am. Chem. Soc. 2007, 129, 2446.

14. Liu, F.; Concepcion, J. J.; Jurss, J. W.; Cardolaccia, T.; Templeton, J. L.; Meyer, T. J.; Inorg. Chem. 2008, 47, 1727.

15. Chen, Z. F.; Concepcion, J. J.; Meyer, T. J.; Dalton Trans. 2011 , 40, 3789.

16. Markle, T. F.; Zhang, M. T.; Santoni, M. P.; Johannissen, L. O.; Hammarstrom, L.; J. Phys. Chem. B 2016, 35, 9308.

17. Reece, S. Y.; Nocera, D. G.; J. Am. Chem. Soc. 2005, 127, 9448.

18. Ishikita, H.; Soudackov, A. V.; Hammes-Schiffer, S.; J. Am. Chem. Soc. 2007, 129, 11146.

19. Kuss-Petermann, M.; Wolf, H.; Stalke, D.; Wenger, O. S.; J. Am. Chem. Soc. 2012, 134, 12844.

20. Bronner, C.; Wenger, O. S.; Inorg. Chem. 2012, 51, 8275.

21. Bonn, A. G.; Neuburger, M.; Wenger, O. S.; Inorg. Chem. 2014, 53, 11075 .

22. Liao, R. Z.; Siegbahn, P. E. M.; ACS Catal. 2014, 4, 3937.

23. Petronilho, A.; Llobet, A.; Abrecht, M.; Inorg. Chem. 2014, 53, 12896.

24. Stewart, D. J.; Brennaman, M. K.; Bettis, S. E.; Wang, L.; Binstead, R. A.; Papanikolas, J. M.; Meyer, T. J.; J. Phys. Chem. Lett. 2011, 2, 1844.

25. Sousa, S. F.; Sampaio, R. N.; Barbosa Neto, N. M.; Machado, A. E. H.; Patrocinio, A. O. T.; Photochem. Photobiol. Sci. 2014, $13,1213$.

26. Pavlishchuk, V. V.; Addison, A. W.; Inorg. Chim. Acta 2000 , 298, 97.

27. Worl, L. A.; Duesing, R.; Chen, P. Y.; Dellaciana, L.; Meyer, T. J.; J. Chem. Soc. Dalton Trans. 1991, 849.

28. Ramos, L. D.; Sampaio, R. N.; de Assis, F. F.; de Oliveira, K. T.; Homem-de-Mello, P.; Patrocinio, A. O. T.; Frin, K. P. M.; Dalton Trans. 2016, 45, 11688.
29. Zhao, Y.; Truhlar, D. G.; Chem. Phys. Lett. 2011, 502, 1.

30. Schuchardt, K. L.; Didier, B. T.; Elsethagen, T.; Sun, L.; Gurumoorthi, V.; Chase, J.; Li, J.; Windus, T. L.; J. Chem. Inf. Model. 2007, 47, 1045.

31. Pantazis, D. A.; Chen, X.-Y.; Landis, C. R.; Neese, F.; J. Chem. Theory Comput. 2008, 4, 908.

32. Weigend, F.; Ahlrichs, R.; Phys. Chem. Chem. Phys. 2005, 7, 3297.

33. Li, T.; Gao, S.; Li, F.; Cao, R.; J. Colloid Interface Sci. 2009 , $338,500$.

34. Sacksteder, L.; Zipp, A. P.; Brown, E. A.; Streich, J.; Demas, J. N.; Degraff, B. A.; Inorg. Chem. 1990, 29, 4335.

35. Frin, K. M.; Murakami Iha, N. Y.; J. Braz. Chem. Soc. 2006, 17, 1664.

36. Duesing, R.; Tapolsky, G.; Meyer, T. J.; J. Am. Chem. Soc. 1990, $112,5378$.

37. Tapolsky, G.; Duesing, R.; Meyer, T. J.; Inorg. Chem. 1990, 29 , 2285.

38. Lin, R.; Fu, Y.; Brock, C. P.; Guarr, T. F.; Inorg. Chem. 1992, $31,4346$.

39. Caspar, J. V.; Meyer, T. J.; Inorg. Chem. 1983, 22, 2444.

40. Roundhill, D. M.; Photochemistry and Photophysics of Metal Complexes, $1^{\text {st }}$ ed.; Plenum Press: New York, 1994.

41. Brown, H. C.; Determination of Organic Structures by Physical Methods, $1^{\text {st }}$ ed.; Academic Press: New York, 1955.

42. Dawson, R. M. C.; Elliott, D. C.; Elliott, W. H.; Jones, K. M.; Data for Biomechanical Research, $1^{\text {st }}$ ed.; Clarendon Press: Oxford, 1969.

43. Pearce, P. J.; Simkins, R. J. J.; Can. J. Chem. 1968, 46, 241.

44. Markle, T. F.; Rhile, I. J.; Mayer, J. M.; J. Am. Chem. Soc. 2011, $133,17341$.

45. Sutin, N.; Creutz, C.; J. Chem. Educ. 1983, 60, 809.

46. Marcus, R. A.; J. Chem. Phys. 1984, 81, 4494.

47. Binstead, R. A.; Mcguire, M. E.; Dovletoglou, A.; Seok, W. K.; Roecker, L. E.; Meyer, T. J.; J. Am. Chem. Soc. 1992, 114, 173.

Submitted: November 25, 2016 Published online: February 9, 2017 